Journal of Chromatography, 179 (1979) 351-354

(C) Elsevier Scientific Publishing Company, Amsterdam - Printed in The Netherlands

CHROM. 12,117

\title{
Note
}

\section{Gas chromatographic determination of bupirimate in apples and pears}

G. F. ERNST, R. HEUIINK and S. Y. VERVELD-RÖDEK

Food Inspection Service, Nijenoord 6-3552 AS Utrecht (The Netherlands)

(Received May 30th, 1979)

Bupirimate, a substituted pyrimidine (a sulphamate ester of ethirimol, 5-butyl2-ethylamino-6-methylpyrimidin-4-yl-dimethylsulphamate), is a local systemic fungicide that is effective in controlling mildew in roses and apples. It has no significant insecticidal properties and is not poisonous to mites ${ }^{i}$.

Bupirimate formulations are commercially available in the Netherlands as ICI Ivosta Anti-Meeldauw (6826 N), Nimrod spuitpoeder (6827 N) and Nimrod vloeibaar $(6834 \mathrm{~N}) *$. The Dutch tolerance for residues of bupirimate in apples and pears is $0.2 \mathrm{mg} / \mathrm{kg}$, of which at the most $0.1 \mathrm{mg} / \mathrm{kg}$ is the metabolite ethirimol (5-butyl-2ethyl-amino-4-hydroxy-6-methylpyrimidine) ${ }^{2}$.

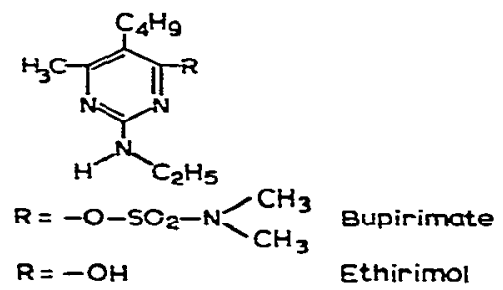

Up to now a direct method to determine bupirimate in apples has not been described in the literature. This paper describes such a method, which includes prior clean-up by column chromatography followed by gas chromatography using an alkali flame ionization detector (AFID) as well as a flame photometric detector equipped with a sulphur filter $(394 \mathrm{~nm})$.

\section{EXPERIMENTAL}

\section{Chemicals and reagents}

Aluminium oxide (Woelm, Eschwege, G.F.R., W 200 neutral, activity super I, particle size $70-290$ mesh) was activated at $200^{\circ}$ for $c a .2 \mathrm{~h}$, then cooled to room temperature in a desiccator. It was then deactivated with water as follows. Water was distributed on the inside of a glass-stoppered bottle, activated aluminium oxide was added in sufficient amount to make the ratio of aluminium oride to water 95:5

- Registered at the Ministry of Agriculture and Fishery of the Netherlands (reg. Nos. 10321T, $9903 \mathrm{~T}$ and $9902 \mathrm{~T}$, respectively). 
$(\mathrm{w} / \mathrm{w})$ and the bottle was shaken for several minutes. The aluminium oxide could be used after $1 \mathrm{~h}$, with occasional shaking prior to use.

For column chromatography, glass columns $(500 \times 8 \mathrm{~mm}$ I.D.) were used, to which quartz-wool, $5 \mathrm{~g}$ of freshly prepared aluminium oxide and $1 \mathrm{~g}$ of sodium sulphate were added successively.

Bupirimate (Dr. S. U. I. Ehrenstorfer, Augsburg, G.F.R.) was dissolved in ethyl acetate; diiution with ethyl acetate yielded standards solutions. All of the reagents were of analytical reagent grade.

\section{Apparatus}

Sulphur mode. A Tracor MT-220 gas chromatograph was equipped with a Melpar 200 AT flame photometric detector (394 nm sulphur filter) and a Honeywell FB 80 recorder with a sensitivity of $1 \mathrm{mV}$. The column (pyrex U-shape, $75 \times 0.3 \mathrm{~cm}$ I.D.) was packed with $10 \%$ OV-101 on Gas-Chrom Q 60-80 mesh. The chromatographic conditions were as follows: injector temperature, $225^{\circ}$; detector temperature, $200^{\circ}$; column temperature, $215^{\circ}$; carrier gas (nitrogen) flow-rate, $50 \mathrm{ml} / \mathrm{min}$; hydrogen flow-rate, $150 \mathrm{ml} / \mathrm{min}$; oxygen flow-rate, $15 \mathrm{ml} / \mathrm{min}$; air flow-rate, $40 \mathrm{ml} / \mathrm{min}$; chart speed, $5 \mathrm{~mm} / \mathrm{min}$.

Nitrogen mode. A Hewlett-Packard 5710A gas chromatograph was equipped with a dual nitrogen-phosphorus flame ionization detector model $18789 \mathrm{~A}$ and a Honeywell FB 80 recorder with a sensitivity of $1 \mathrm{mV}$. The column (pyrex, $50 \times 0.3$ cm I.D.) was packed with $10 \%$ OV-101 on Gas-Chrom Q 60-80 mesh. The chromatographic conditions were as follows: injector temperature, $250^{\circ}$; detector temperature, $300^{\circ}$; column temperature, $200^{\circ}$; carrier gas (helium) flow-rate, $30 \mathrm{ml} / \mathrm{min}$; hydrogen flow-rate, $3 \mathrm{ml} / \mathrm{min}$; air flow-rate, $50 \mathrm{ml} / \mathrm{min}$; chart speed $5 \mathrm{~mm} / \mathrm{min}$.

\section{Extraction}

The sample was cut in a food cutter and extracted by macerating $50 \mathrm{~g}$ of cut sample with $100 \mathrm{ml}$ of dichloromethane and $50 \mathrm{~g}$ of anhydrous sodium sulphate in an Ultra Turrax at moderate speed. The macerate was centrifuged for $5 \mathrm{~min}$ at 2500 $g$ and the extract was collected. A $25-\mathrm{ml}$ volume of the extract was evaporated to dryness in a rotary vacuum evaporator. The residue was reconstituted in $1 \mathrm{ml}$ of ethyl acetate.

\section{Clean-up (optional)}

A $25-\mathrm{ml}$ volume of the extract was evaporated to dryness in a rotary vacuum evaporator. The residue was transferred quantitatively into an aluminium oxide column, using $c a .2 \mathrm{ml}$ of hexane-dichloromethane $(1: 1)$. The column was eluted with $80 \mathrm{ml}$ of hexane-dichloromethane $(4: 1)$ and the eluate (eluate I) was discarded. The column was then eluted with $80 \mathrm{ml}$ of dichloromethane, the eluate (eluate II) was evaporated to dryness and the residue was dissolved in $1 \mathrm{ml}$ of ethyl acetate.

Gas chromatography

A $5-\mu l$ of the solution was injected into the gas chromatograph. Standard solutions containing $1-10 \mathrm{ng}$ of bupirimate per $5 \mu \mathrm{l}$ were also injected. 

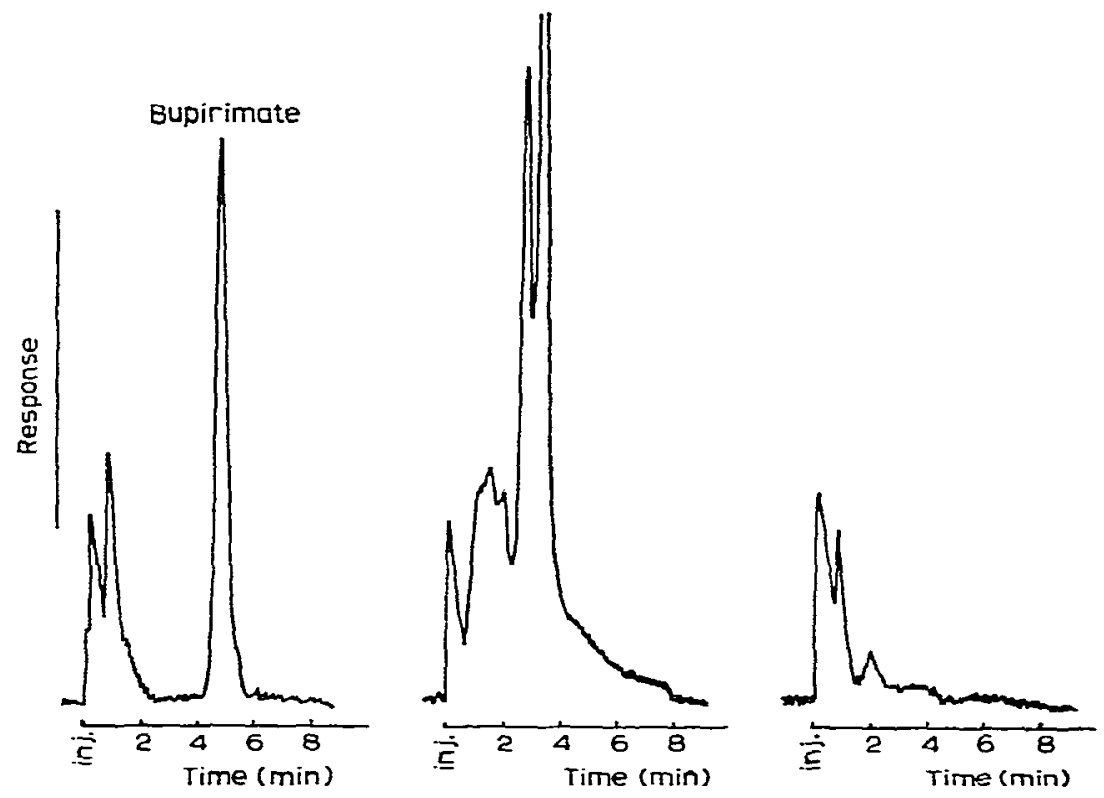

Fig. 1. Chromatogram of $20 \mathrm{ng}$ of bupirimate standard. Column, $75 \times 0.3 \mathrm{~cm} \mathrm{I.D.,} 10 \%$ OV-101 on Gas-Chrom Q 60-80 mesh; injector temp., $225^{\circ}$; detector temp., $200^{\circ}$; column temp., $215^{\circ}$; flow-rate, carrier gas (nitrogen), $50 \mathrm{ml} / \mathrm{min}$, hydrogen, $150 \mathrm{ml} / \mathrm{min}$, oxygen, $15 \mathrm{ml} / \mathrm{min}$, air, $40 \mathrm{ml} / \mathrm{min}$; chart speed, $5 \mathrm{~mm} / \mathrm{min}$; flame photometric detector ( $394 \mathrm{~nm}$ sulphur filter).

Fig. 2. Chromatogram of extract from blank apple without clean-up. Conditions as in Fig. 1.

Fig. 3. Chromatogram of eluate II from blank apple. Conditions as in Fig. 1.
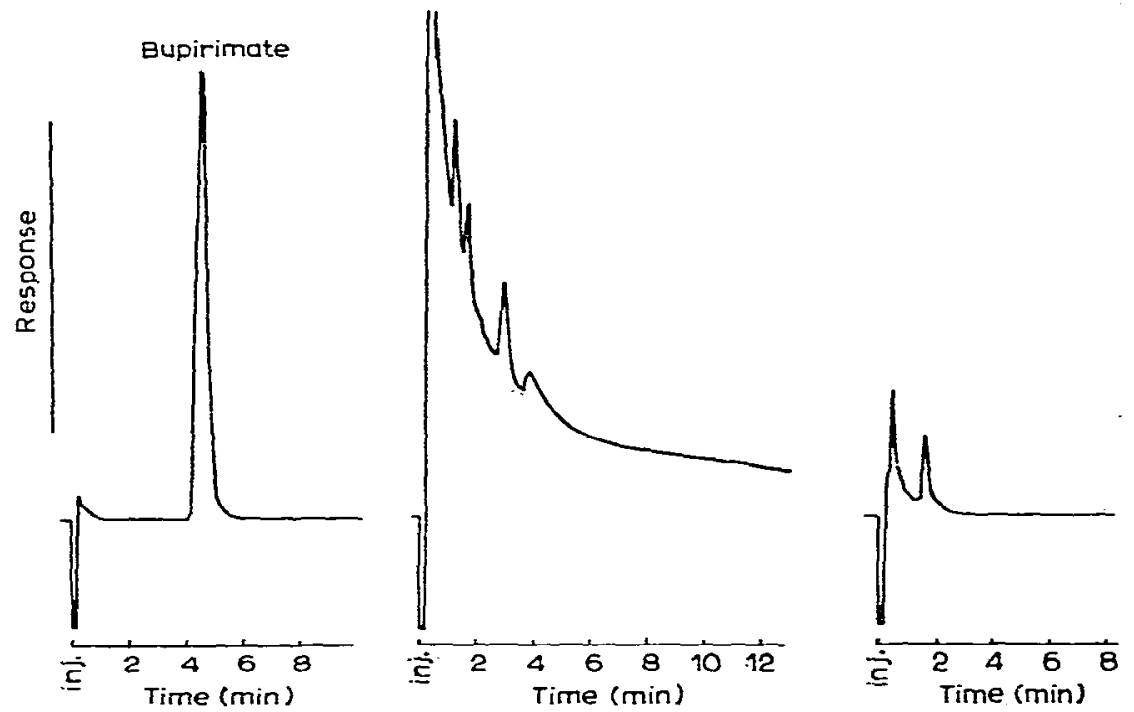

Fig. 4. Chromatogram of $10 \mathrm{ng}$ of bupirimate standard. Column, $50 \times 0.3 \mathrm{~cm} \mathrm{I.D.,} 10 \% 0 \mathrm{OV}-101$ on Gas-Chrom Q 60-80 mesh; injector temp., $250^{\circ}$; detector temp., $300^{\circ}$, column temp., $200^{\circ}$; flow-rate, carrier gas (helium), $30 \mathrm{ml} / \mathrm{min}$, hydrogen, $3 \mathrm{ml} / \mathrm{min}$, air, $50 \mathrm{ml} / \mathrm{min}$; chart -speed ,5 mm/min; dual nitrogen-phosphorus flame ionization detector.

Fig. 5. Chromatogram of extract from blank apple without clean-up. Conditions as in Fig. 4.

Fig. 6. Chromatogram of eluate II from blank apple. Conditions as in Fig. 4. 


\section{RESULTS AND DISCUSSION}

Chromatograms of bupirimate standard and apple samples are shown in Figs. 1-6. The interference in the chromatograms of the uncleancd apple samples (Figs. 2 and 5 ) is dependent on the apple variety. For routine or screening work the optional clean-up can be omitted.

The flame photometric detector with sulphur filter as well as the AFID showed a linear response over a bupirimate range of $0.03-0.15 \mathrm{mg} / \mathrm{kg}$ (2-10 $\mathrm{ng}$ absolute).

The recovery of bupirimate was determined by analysing apple samples spiked with bupirimate at levels from 0.05 to $0.3 \mathrm{mg} / \mathrm{kg}$. The results are shown in Table I. The limit of detection was ca. $0.02 \mathrm{mg} / \mathrm{kg}$ for both detectors.

\section{TABLE I}

RECOVERIES OF BUPIRIMATE FROM BLANK APPLE TREATED WITH BUPIRIMATE STANDARD SOLUTIONS FOLLOWING CLEAN-UP PROCEDURE

Average values are given for five recovery experiments with both detectors, each carried out with three concentrations of bupirimate.

\begin{tabular}{ll}
\hline Bupirimate added to apple (ppm) & Average recovery (\%) \\
\hline 0.05 & 98.4 \\
0.10 & 98.6 \\
0.30 & 97.4 \\
\hline
\end{tabular}

The metabolite of bupirimate, ethirimol, could be determined gas chromatographically with AFID after derivatization with diazomethane ${ }^{3}$.

\section{REFERENCES}

1 Gids voor ziekten- en onkruidbestrijding in land- en tuinbouw, 6th ed., Consulentschappen voor Plantenziektenbestrijding, Wageningen, The Netherlands, 1977, p. 65.

2 Bestrijdingsmiddelenwet, Uitvocringsvoorschriften (C II-4), Vermande Zonen, IJmuiden, The Netherlands, 1978.

3 M. D. Edwards, Anal. Methods Pestic. Plant Growth Regul., 8 (1976) 291-297. 